\title{
CONFERENCIA MAGISTRAL INAUGURACIÓN AÑO ACADÉMICO 2011 FACULTAD DE CIENCIAS JURÍDICAS Y SOCIALES. UNIVERSIDAD DE TALCA: REFORMA PROCESAL CIVIL*
}

Raúl Tavolari Oliveros ${ }^{* *}$

Muy buenas tardes autoridades académicas, alumnas, alumnos, señoras y señores, amigos. Desde luego, no incurro en un lugar común si digo que me resulta extremadamente grato estar en este ambiente académico, lo es por muchísimas razones. Soy un admirador por haber dedicado tanto tiempo de mi vida a la docencia académica, soy un admirador del trabajo académico exigente, bien hecho, bien logrado. Esta es una característica que acompaña a esta Facultad, una característica que ha trascendido largamente de los confines de la Región y es hoy día un hecho conocido en el país, eso me llena de agrado y de orgullo, hay muchas razones para eso, tengo queridísimos amigos, tengo gente a la que aprecio y admiro muchísimo desempeñando las labores académicas, en consecuencia, me siento gratificado de ver caras amigas y de ver tanta gente joven en esta aula. Los esfuerzos de aquellos que hemos tenido la suerte de estar en la vida académica sólo tienen sentido si están orientados hacia las generaciones que vienen, hacia la gente que nos seguirá, hacia quienes toman la bandera para seguir adelante con la tarea, es por eso que me parece en esa perspectiva vale el esfuerzo que uno haga para compartir inquietudes y a veces conocimientos. Doy, además, un agradecimiento especial a los distinguidos amigos y académicos, el distinguido decano don Jorge del Picó y a mi queridísimo amigo y colega Diego Palomo por esta invitación y sin más entro a hablar del tema que me han pedido para estar aquí.

Se trata simplemente y nada menos de hablar con ustedes de la Reforma Procesal Civil en general y de la nuestra en particular. A mí, usualmente me han asaltado dudas en torno a las razones por qué los países entran a veces

\footnotetext{
* Colaboración recibida el 23 de mayo y aprobada el 20 de septiembre de 2011.

** Transcripción de la conferencia del Profesor Raúl Tavolari Oliveros, actual Presidente del Instituto Iberoamericano de Derecho Procesal, en la inauguración del año académico de la Facultad de Ciencias Jurídicas y Sociales de la Universidad de Talca. Ceremonia realizada el día 23 de mayo de 2011. Documento preparado por Williams Valenzuela Villalobos, Ayudante del Departamento de Derecho Penal, Procesal y del Trabajo. Correo electrónico: willysva@hotmail.com.
} 
en procesos reformadores, por qué razón se comparten, qué ocurre, para que agite de tarde en tarde a sectores del mundo esta inquietud reformadora. En América Latina esto lo hemos vivido muchísimas veces, lo vivimos de un modo notable en los años noventa cuando, del Río Grande hacia el sur, toda América Latina se agitó y convulsionó modificando los Códigos del proceso penal. Ese fue un movimiento que nos unió de un extremo a otro. Y nos unió por muchísimas razones, pero nos unió además en metas y propósitos comunes, cuando cumplida en mayor o en menor medida la tarea, echamos la vista atrás veremos que prácticamente todos llegamos casi a los mismos lugares o nos quedó en claro que perseguíamos idénticas finalidades, avanzando muchísimo en ese terreno. Nosotros en Chile, además, tenemos la peculiaridad de haber comenzado la carrera, siendo literal, como los últimos y la hemos concluido, y lo digo casi bajando la voz para que no se me malentienda, la hemos concluido probablemente ocupando el primer lugar. El primer lugar en modernidad, en avances, en audacia de algunas soluciones, en modos de enfrentar ese problema que es el proceso penal, bien por esa etapa, pero está largamente superada, ya se han cumplido diez años de un Código Procesal Penal y era hora ya hace mucho tiempo que nos ocupáramos de, para los que estamos en el mundo del proceso constituye la base, constituye el tronco matriz, qué es el proceso civil. Ya saben ustedes que para éste existen opiniones discrepantes, si se recorren algunas realidades universitarias europeas, por ejemplo, incluso latinoamericanas, se advertirá que en algunas de ellas hay una escisión muy profunda en lo que es el proceso penal y lo que es el proceso civil, así por ejemplo en Alemania, la enseñanza del proceso penal está confiada a los académicos del Derecho Penal, ocurre lo propio en Argentina, si ustedes leen a Maier o Cafferata Nores, se encontrarán con ardorosos argumentos para demostrar por qué razón ese proceso penal tiene que estar confiado a los penalistas. Las razones, ya digo son fuertes y están sustentadas por gente extremadamente inteligente, pero claro, a veces los que estamos en la ribera contraria no nos convencen en lo absoluto o nos convencen de poca manera. Nuestra común vertiente latinoamericana que se entronca, pues, en el derecho de la península ibérica, básicamente en España, nos ha conducido por un camino distinto. Nosotros pensamos que el proceso civil es el gran tronco desde que, como dijo el clásico se desgajan ramas, que van formando modalidades separadas, pero que nunca se terminan de distanciar enteramente de lo que es el proceso civil. Y esto que para mí es una realidad y que yo creo que es importante ponerlo en práctica, no sólo en la letra no sólo en el discurso ni sólo en la programación, sino en la vida cotidiana, desde luego en la vida académica y esto, en consecuencia, es lo que me lleva a mí a, por ejemplo, propugnar que sean académicos dedicados a la Ciencia procesal los que impartan la ciencia, el proceso civil, la regulación penal y los que 
impartan además otras ramas procesales que con el transcurrir del tiempo han alcanzado alturas insospechadas y, además, tienen una importancia práctica y cotidiana en nuestra vida común enorme, estoy pensando en nada más que en el ámbito del proceso laboral, que como ustedes probablemente están informados hizo algunas reformas en su ordenamiento procedimental en los últimos cinco o seis años, extremadamente llamativos, originales, provocativos, pero en mi modesta perspectiva exhibiendo claramente falencias, que yo atribuyo a la entera marginación de la gente que tiene, como interés básico y central, la Ciencia procesal y no algunas otras sustantivas, como sería, por ejemplo, el Derecho del Trabajo.

Ha sucedido, como sabemos todos, que desde entonces (años noventa) a esta parte en Chile hemos tenido un conjunto de reformas, en distintos órdenes, algunas relevantes de sagrado sumo. Reparen, por ejemplo, en lo que significa la creación de un tribunal de defensa de la libre competencia y toda la actividad que se ha venido generando en ese terrero que antes estaba entregado a algunas comisiones, de un modo enteramente administrativo, de un modo profundamente insatisfactorio, plagado de irregularidades o de decisiones que generaban enormes dudas, hoy día tenemos ahí una rama de procesos, autónomos, bien construidos sobre un tribunal independiente; en fin, hay un avance enorme, y así uno podría pasar una rápida revista a distintas áreas, mencioné el proceso laboral, sólo cito esta cosa que es impresionante como el recurso de unificación de la jurisprudencia, lo que nadie en Chile se había atrevido a abordar. Allá lo abordaron con una simpleza conmovedora, porque de pronto los resultados no han sido los que uno esperaba. Que tal el examen de lo que pasó en el ámbito del Derecho de Familia, con una trascendencia nacional, que finalmente ocupó páginas de diarios y nuestros noticieros. Colapsado el tema tribunalicio y básicamente por algunas deficiencias estructurales, pero ahí está la reforma al proceso de familia, avanzando con soluciones nuevas, con respuestas que no teníamos incorporadas a nuestro ordenamiento.

$\mathrm{Y}$ esto se proyecta por todos lados a partir, sin embargo, del esfuerzo mayor, que fue ese Código Procesal Penal, cuyos estudios echamos a andar en el año noventa y cuatro, hasta culminar en el dos mil con la vigencia del Código, y entonces al que hubiera llegado de otras latitudes le hubiera asaltado una duda o a lo menos una inquietud enorme, qué efecto práctico tiene que en un país se reformen las facetas o las parcelas secundarias procesales, sin que se eche mano al tronco, a la cuestión fundamental, porque lo razonable es que si concebimos cada uno de nosotros agrupados acá para echar a andar una reforma, concebimos el modo de trabajo, probablemente diríamos pongámonos de acuerdo, hagamos una gran modificación central, establezcamos un gran estatuto procesal y, luego, en función de necesidades, requerimientos o exigencias, de algunas ramas del Derecho específicas, demos respuestas parciales apropia- 
das a esos requerimientos, pero con este camino nos ahorraremos un trabajo enorme que consiste en regular en función de cada una de estas regulaciones procedimentales especiales todo el sistema. Bastará, si trabajamos del modo que yo estoy proponiendo, que sólo nos ocupemos de la respuesta específica que cada ámbito demanda y el resto lo refiramos al tronco común, fácil, simple, bueno para los operadores, evita respuestas contradictorias, en fin, parece el modo que impone el sentido común, pero como acontece, con más frecuencia de lo que uno quisiera, en Chile nos olvidamos de ese sentido común, y que lo que hicimos, hicimos todas las reformas procedimentales parciales previas y dejamos pendientes las del proceso civil y entonces hoy día nos sentamos a analizar la reforma al proceso civil.

Es muy Ilamativo que en América Latina, cuando hablamos de reformas procesales, no estamos pensando en verdad en cambiar una norma o agregar otra, estamos pensando simplemente en remplazar Códigos completos, de modo que a la voz reforma del proceso civil hay que entender la sustitución del Código vigente por uno distinto. Es la tarea a la que nos hemos abocado ahora, y no hemos abocado, sin embargo, con entusiasmo, nos hemos abocado interesados, pero nos hemos abocado a ella constreñidos por ciertas cuestiones difíciles de superar. Concebiría alguien hoy día que respuestas fundamentales en el proceso civil que se nos vienen, puedan alejarse grandemente de lo que ya está resuelto en el proceso penal, podrían haber respuestas a cuestiones concretas procedimentales adoptadas en materia laboral, familiar y penal, que hoy día fueran enteramente distintas en el ámbito del proceso civil. La respuesta es obviamente negativa, o sea, lo que es claro es que el nuevo proceso civil chileno tiene que nutrirse de aquellos aportes que conformaron las reformas que ya conocemos, esto no es malo per se, esto no significa un San Benito del cual no podamos librarnos y que nos acompaña de un modo incapaz de superarse, de ninguna manera, esas en general, las respuestas que ya adoptamos en el país son satisfactorias, recogen avances dogmáticos, recogen avances jurisprudenciales, se ajustan, en general, a los requerimientos de los operadores, sólo que, casi por un tema conceptual, uno no puede sino deplorar que esta regulación del Código Procesal Civil que ha de ser, que habría de ser, el Código madre, se emprendan una vez ya que todos los otros sistemas procesales están estructurados, esa es la limitante y eso condiciona, incluso, mi exposición de hoy día, lo que para la gratificación de todos, la acorta bastante.

A la pregunta de qué vamos hacer con el nuevo Código Procesal Civil, se puede contestar de un modo muy simple: vamos a tomar los grandes lineamientos que ya tenemos en vigencia y los vamos a adaptar de modo que nadie puede llamar a sorpresa si cuento que lo que estamos haciendo o lo que viene o lo que se va a proponer es un proceso estructurado en base a audiencias. Una audiencia preparatoria, preliminar o como ustedes la quieran denominar 
y una audiencia central o de juicio, este es el mecanismo del Código Laboral, el mecanismo de familia, el mecanismo del proceso laboral nuevo. Esa es la columna vertebral del proceso que vamos a hacer, un proceso por audiencias, eso es lo que vamos a hacer. Un poco por respeto al Instituto Iberoamericano, hay que reconocer que estas ideas están tomadas de los Códigos modelos, el Instituto Iberoamericano estuvo trabajando hasta el año noventa y, probablemente unos veinticuatro o veinticinco años antes, en la elaboración de Códigos modelos, se llamó a los procesalistas de todo Iberoamérica y se les invitó a participar en la redacción de un Código de proceso penal y un Código de proceso civil. Ambos Códigos no pretendieron ser aplicados como textos positivos en ningún país, sino tuvieron la muchísimo más moderna intención de constituirse en referentes o modelos que las legislaciones pudieran contemplar, para adaptar a sus propias realidades esas respuestas que venían de este mundo heterogéneo, pero al final tan común como es este mundo del proceso y lo que es lo mismo el mundo del Derecho americano. De allá tomamos las ideas, y por eso estructuramos este proceso por audiencias, que un proceso predominantemente oral, fundamentalmente oral, pero definitivamente no es un proceso exclusivamente oral. Aquí, estimados alumnos, déjenme decirles que los años, el mirar atrás, el haberse equivocado ayuda a desmitificar ciertas creencias, si ustedes revisan cualquier texto clásico se hacen dos columnas para comparar lo que es el proceso oral con el proceso escrito, y en ellas casi uno podría poner un más y un menos, pues a un lado se suman las virtudes y al otro los defectos, de modo tal que al final de la lectura uno queda convencido, al igual que en las viejas películas del oeste americano, los buenos están a un lado, los que preconizan la oralidad; y los malos, antiguos y no dados a los cambios en el otro lado, son los partidarios del proceso escrito. Pero déjenme decirles que desde esa atalaya a que acabo de referirme, la que dan los años, la que da la experiencia, la que dan los errores cometidos, hoy día yo, al menos, miro con algún grado de escepticismo estas distinciones tan tajantes, sin duda que hay enormes virtudes en la oralidad, pero las hay también en el proceso escrito. Y voy a referirme al punto en un par de minutos, pero voy a adelantar, yo trato de hablar exponiendo lo que es mi experiencia de vida, yo soy fundamentalmente un abogado de ejercicio profesional que practica la docencia universitaria, y la hago francamente y sin un afán exagerado, con gran humildad porque reconozco lo que puede significar una vida exclusivamente dedicada a la academia, yo no la tengo, yo he sido toda mi vida un abogado que ejerce con entusiasmo, con esfuerzo, con interés en la cátedra universitaria. Pero eso que siento, y que lo expreso en los términos que acabo de señalar, me otorga además, creo yo, una visión especial. No creo en las soluciones que arrancan de un solo sector, no creo a pie juntillas en aquellos que nos postulan desde la perspectiva de la imparticion de la justicia, miro con recelo los que nos pre- 
conizan exclusivamente quienes están en la trinchera del ejercicio profesional, y con idéntica cautela miro aquella propuesta que viene, exclusivamente, del mundo de la academia, y es que resulta tan fácil justificarlo, son visiones algunas extremadamente relevantes, extremadamente importantes, pero no por eso menos parciales, esto se advierte a la vuelta de cada esquina. Reparen, por favor, en aquellas leyes que en pro de la agilidad, de la calidad del servicio, de la eficiencia de la imparticion de la justicia, excluyen a los abogados y que cuentan con un apoyo caluroso del Poder Judicial, muy frecuente. Cité hace un minuto la patética experiencia que tuvimos con la reforma de los tribunales de familia, que comenzaba diciendo a los abogados afuera. La visión del juez es una visión importante, pero lo es desde una perspectiva del problema. Qué tal la visión sólo de la academia, hay estudios académicos que son de verdad sobrecogedores, en el sentido que revelan un conocimiento tan profundo de la ciencia que no queda sino prestarles aceptación casi con veneración, y los hay por montones. Siempre refiero a esto, especialmente a la ciencia jurídica europea, alemana, española, italiana, son los ámbitos en que me desenvuelvo con mayor soltura, excluyo la francesa, por eso mis admiraciones van a otras, pues en ellas me muevo con alguna facilidad. Pero allí también de la gente que me merece mi admiración me sorprende: algunas respuestas que demuestran la falta de lo otro, y esto no es nada sorprendente: ninguno de nosotros entregaría la cátedra de cirugía a quien no hubiere tenido un bisturí en las manos, verdad, eso nos parece inaceptable, por eso es que hay que combinar, $y$ he querido reafirmar mis palabras con un ejemplo concreto, alguien que me conmueve, Calamandrei, tuvo una trayectoria jurídica, política, académica formidable. Respecto a Calamandrei, un comentarista gran admirador suyo escribió, Calamandrei fue un abogado y lo fue con todas las potencias de su alma, fue básicamente un abogado, fue político y fue un notable académico. Es la persona a la que le debemos la actual estructura de la casación. Taruffo ha escrito un libro no hace mucho tiempo, donde plantea las dificultades o los esfuerzos de llevar la casación en un sentido determinado. Escribió antes de los veinticinco años una obra monumental sobre casación, pero fíjense lo que dice, contando una anécdota que la leeré rápidamente para no aburrirlos, se trataba del tema de reajuste del pago de una pensión de una herencia a la que aspiraban los hijos naturales, abandonados por sus padres y extremadamente pobres, eran hijos naturales en la Italia de la primera mitad del siglo pasado, donde obviamente el estatus de los hijos naturales era un estatus desmejorado y cuando el padre los había abandonado esta pareja de hijos se habían sumido a la pobreza. Ocurrió, sin embargo, que el padre murió y en su testamento sólo dejó favorecidos a los hijos legítimos. Esta pareja de hijos tomó conocimiento de las circunstancias e interpuso una demanda. Allá en el año 41, cuando Italia se encontraba sumida en la guerra, y probablemente ustedes sabrán la 
otra parte, cuando había una crisis financiera en Italia tremenda, porque hubo una recesión y entre las cosas que intentó hacer Alemania fue eliminar la lira y reemplazarla por el marco, y eso creó una crisis económica enorme.

Bien, la causa se sustanció durante diez años. Terminó con un fallo de la Corte de Casación a comienzos de la década de los cincuenta, fallo que obviamente dictado por un tribunal de derecho como lo era la Corte de casación, por estrictas consideraciones jurídicas y lógicas, sin hacer la menor claudicación a la equidad, resolvió que el monto que le correspondía a este par de hijos naturales era el valor nominal del día de la muerte del causante, y en consecuencia que Italia había sufrido una inflación de varios miles por cientos durante una década, había desvalorizado su moneda a extremos absurdos, de modo que la herencia en verdad no alcanzaba a comprar un diario, y Calamandrei escribe: recuerdo como uno de los momentos más tristes de mi vida profesional aquel que tuve que anunciar la derrota a aquellos dos pobrecitos, personas humildes, desconocedoras de semejantes exigencias humanas del silogizar jurídico, no conseguían comprender la aparente monstruosidad. Uno de ellos en el momento de regresar a su pueblo me preguntó con lágrimas en los ojos ¿pero que mal les hemos hecho a ustedes para merecer tanto daño?, y concluye Calamandrei, y yo abogado que tenía la garganta apretada por la angustia, no supe qué responderles.

Por qué traigo este episodio a colación, para enfatizar la idea de que una reforma del proceso y de que todas la reformas en el derecho tienen que ser el fruto de la comunión de opiniones de los distintos operadores, en el ámbito procedimental la exigencia de que junto a los jueces y a los profesores dogmáticos y académicos opinen los abogados, a mí me parece ineludible y esta es una receta para el futuro y una receta para el día de hoy, no se pueden hacer reformas sin escucharlos a todos. Esto tiene que ser como una sinfonía en que un director armonice las entradas y salidas de quienes intervienen, pero tienen que estar todos opinando, todos participando. Primera gran cuestión, pues a la hora de hablar de reformas los invitados a participar en ellas, todos, merecen y deben ser escuchados, so riesgos de que en caso contrario las reformas no satisfagan verdaderamente las exigencias. La segunda cuestión, después de resolver quiénes han de participar en el proceso reformador, es determinar hacia dónde queremos ir con las reformas, qué queremos obtener. Alguien puede responder: nos movemos reformando en procura de una mejor justicia, y quien en un ámbito como éste, académico, la facultad de derecho, puede discrepar de eso, sin duda que nadie, ¿verdad? Y que la justicia es un valor inmanente al hombre, tampoco es una cuestión discutible y basta mirar la historia para ver como lo de siempre tarde a propósito de cualquier episodio aparece siempre sobre la mesa el valor de la justicia, de modo que tampoco nos detengamos en eso porque resulta innecesario. 
El punto es que esto ahora tenemos que ajustarlo a cosas concretas, y entonces yo diría que la tercera fórmula para reformar es de cara a saber hacia dónde queremos ir, conocer en qué lugar estamos, conocer cuál es nuestra realidad. Permítanme entonces aventurar una idea, con la marcada excepción de la reforma del proceso penal en la que seriamente se intentó contar con información para dar respuestas, y respecto a la cual sabemos todos los que participamos que pudimos recopilar mejor información, pero salvo esa excepción de la reforma al proceso penal, en Chile, tengo la sensación en la piel, que seguimos reformando como don Andrés Bello en el siglo XIX o como lo hizo ese notable jurisconsulto Egidio Ballesteros, es decir, poniendo sobre la mesa antes que nada el talento, la capacidad, la invención y creatividad, pero nos falta, señores, la información dura. Déjenme ponerles un ejemplo, casi como un rumor que ha devenido en axioma: se dice que el ingreso de los tribunales civiles, y voy a decirlo de esta manera para no extenderme indebidamente al ámbito de la Región Metropolitana o de Santiago, aún con mayor limitación el $80 \%$ de los ingresos corresponde a ejecuciones, o juicios ejecutivos o preparación de la vía ejecutiva, o cuestiones relativamente vinculadas al tema. Eso condiciona muchísimo lo que haya de hacerse. Últimos estudios dicen que en esa misma comuna donde cada tribunal, hay 30 , tienen una media de 27 a 30 mil causas en el año; últimos estudios, sin embargo, permiten sospechar que el porcentaje de ingresos de juicios vinculados con la ejecución excede del 95\%. Si eso es así, si esto se confirmara, no les parece que uno debiera preguntarse dediquémonos a resolver el tema que nos plantean las ejecuciones, busquemos tribunales especiales de ejecución, cambiemos el régimen de ejecuciones, porque si lo otro es menos del $5 \%$, la verdad es que no resulta muy justificado volcar allí los esfuerzos. Vamos a suponer que las estadísticas están equivocadas y que no es tanto como les estoy diciendo, pero los invito a aquel que esté en una noche de insomnio a que ingrese en la página web del Poder Judicial, e invente cualquier número del 358 y lo ponga en la consulta de causas, 358 es un ingreso que comparten todos los tribunales, de Arica a Magallanes, bien 358 , todos los tribunales tienen una causa de ese tipo, pongan la 1.700 también, pongan la 3.400 y a lo mejor algunos no va a tener, pongan la 12.000 y todos los juzgados de Santiago van a tener una causa de ésas. Por qué sirve este ejercicio, porque cuando uno ve a qué causa corresponde la causa 1.350 de los juzgados de letras de Chile, verá que probablemente el noventa por ciento son ejecuciones, entonces, no hay que saber ciencias de las estadísticas, simplemente hay que comprobar la realidad. Así, creo yo, uno puede difundir esta inquietud, no podemos reformar sin conocer el terreno que pisamos, $y$ tenemos una gran deficiencia, la información que manejamos es, en general, insuficiente.

Bien, cuarto elemento en la reforma, en el proceso reformador, ¿ hacia dónde volcamos la mirada?, ¿de dónde sacamos el modelo?, ¿cuál es el referente 
al cual atender? En Chile, hemos sufrido de una enfermedad endémica, en el ámbito del derecho, la sufrimos hasta la postrimería del siglo XX, consistió en la imposibilidad de levantar la mirada, en la imposibilidad de contemplar lo que pasaba en el resto del mundo, es impresionante cómo nos mantuvimos aislados sin recibir la información, sin ser permeables respecto a lo que ocurría en el resto del mundo. Esa realidad hoy está superada, hoy sí sabemos, compartimos, entendemos, vivimos lo que pasa en el resto del mundo, y entonces otra vez viene el Ilamado de atención: Brasil tiene 191 millones de habitantes, Uruguay tiene 3.4 millones de habitantes. Uruguay tiene en vigor, desde hace casi 18 años, un Código general del proceso, que busca, prácticamente, abolir el sistema escrito. Esa solución que sirve, prácticamente, en todos los tribunales de Montevideo, Montevideo tiene 1 millón 100 mil habitantes. Es enteramente inimaginable en Sao Pablo, y entonces aventuro una idea, nunca en Brasil, que tiene un único Código de proceso civil, nunca se establecerá un sistema oral, es imposible, esa cantidad de justiciables hace que un régimen oral no pueda prosperar, y ipor qué esto es importante? Porque hay que sacar una conclusión que es más que obvia, lo que algunos sirve a otros es absolutamente inaceptable; entonces, las soluciones hay que tomarlas con beneficio de inventario, diríamos en la jerga común nuestra, y lo digo particularmente, porque ha suscitado en Chile un tema relevante, no sólo en Chile, en toda Iberoamérica hay vigente un Código extremadamente moderno, es la nueva ley de enjuiciamiento española del año 2000. Hemos sido tributarios, por siglos, del derecho español. Algunos de nuestros Códigos tienen copiadas, sin rubor alguno, decenas de disposiciones, no es la hora para decir olvidémonos de lo que pasa en España, desde luego que no. Pero así como importa saber cómo allá han contestado algunas preguntas, porque tienen un mundo del derecho más desarrollado que el nuestro, y eso es evidente, así como tenemos que ver para allá para saber cuáles son las soluciones, debemos tener la capacidad de determinar cuáles de esas respuestas nos resultan adecuadas. Por favor, en Chile hicimos un proyecto de Código, que es el que hoy se está revisando, que si ustedes lo revisan, tiene hasta expresiones idiomáticas que nos son ajenas, tiene idioma español, con modismos que no usamos en Chile, y eso, obviamente, es la negación de un sistema de reformas, porque hay una política pública, una regla básica de política pública, que consiste en adecuar la solución que se propone a los requerimientos del ciudadano. Entonces, en esta parte, y con esto concluyo el capítulo introductorio y entro rápidamente en las dos ideas que quiero dar sobre el fondo, a la hora de hablar sobre reformas en el proceso civil hay que tomar en cuenta los elementos con que debe trabajar, para no dejarse influir más allá de la cuenta por otros, que siendo importantes, merecen, sin embargo, un trato parcial, un trato crítico, en el buen sentido de la expresión. 
¿Qué pasó con el Código de proceso civil chileno?, probablemente están todos ustedes enterados que está pendiente, está sometido a la aprobación del parlamento chileno, un proyecto de Código completo. Ese proyecto de Código fue el fruto de un trabajo de varios años, de académicos de distintas facultades y, en consecuencia, demandó gran esfuerzo, y tiene respuestas y tiene aportes verdaderamente valiosos. Pero, para ser franco, adoleció de un grave problema, faltó una política de trabajo que sistematizara los esfuerzos, y entonces hubo quienes se dedicaron a trabajar en la introducción, por decirlo en términos del viejo Código nuestro, algunos se encargaron de las disposiciones de todo el procedimiento, otros se ocuparon del período de discusión del juicio ordinario, otros se ocuparon de la prueba, otros se ocuparon de los incidentes, otros de los recursos y unos terceros se ocuparon de juicios especiales. A cada cual se le requirió que entregara su proyecto, su trabajo, y eso simplemente se compiló y se transformó en el Código vigente, en el proyecto de Código vigente. No obstante, los muchos y valiosos esfuerzos que se volcaron, la respuesta no pudo ser satisfactoria, porque faltó la armonización, faltó la lectura global, faltó la visión de conjunto, que por la premura del tiempo, no pudo nunca darse. Entonces, ¿qué ha pasado en el último año? Ese trabajo tan valioso, donde tanta gente importante trabajó, se tomó para darle una estructura de conjunto, para que la solución que se proponía en recursos, no fuera estructuralmente contradictoria con aquello que constituía la regla sobre prueba o que las reglas de prueba se ajustaran a temas de introducción o de disposiciones comunes, o sea, se buscó armonizar, y durante un año, que se cumple justamente en estos días, una comisión ahora de muy poca gente, ha sesionado ininterrumpidamente para armonizar este trabajo, y eso está en vísperas de concluirse, probablemente en los dos o tres meses haya un nuevo trabajo, y por favor, quisiera no me malinterpreten, está hecho sobre la base del esfuerzo que significó el proyecto hoy sometido a la aprobación parlamentaria, que no ha sido tratado por el parlamento, y que en definitiva será reemplazado por esto que es lo mismo, estructurado de un modo más armónico.

De ese proyecto nuevo, yo quisiera tocar apenas tres o cuatro puntos que me parecen importantes. En primer lugar, quiero decir que cuando uno habla de un proceso civil, es inevitable resolver como primera medida el tema de los poderes del juez. En un proceso civil, de nuestros días, nuestro siglo XXI, aquello constituye una cuestión básica: ¿Qué poderes le vamos a dar a juez?, en síntesis, hasta dónde queremos que el proceso lo controle, lo dirija el juez y qué rol le corresponde a las partes, y obviamente, como cualquiera de ustedes lo podría decir, me parece a mí que la única solución cabal es aquella que apunte a equilibrios adecuados. Es cierto, el proceso dejó de ser, como en el siglo XIX, cosa de las partes, como decían los alemanes, para transformarse en la sede del ejercicio de una función pública, que es la función jurisdiccional, 
de modo que no puede, meramente, ser el proceso un instrumento, para que las partes simplemente expongan sus cuestiones y le den los ritmos, las velocidades y el destino que les parezca. Hay que tener en cuenta el conflicto público que está involucrado cuando se demanda la actividad jurisdiccional, pero eso que es muy importante, no puede hacer olvidar lo otro, nos movemos en el ámbito de aquello que es renunciable, disponible, en aquello que, en definitiva, cabe tener presente la intervención de un principio de disposición de las partes. Hay que reconocerles a las partes un señorío sobre el proceso que sea compatible con la función pública que a través del proceso se ejerce, esa armonización se va a traducir en muchísimos aspectos, desde luego en uno que es muy importante: el impulso procesal, y el impulso procesal no parece malo confiárselo de manera relevante al tribunal, que sea él, el que, requerida la intervención, pueda disponer un ritmo acelerado para la solución del conflicto, dependiendo ciertamente de la actitud de las partes, pero si el impulso se lo confío al tribunal, algunos institutos los tengo que sacar definitivamente a la realidad, o sea, se acabó, por decirlo de alguna manera, el tema del abandono del procedimiento, porque si el impulso es del juez, mal puedo yo sancionar a las partes con el abandono por la negligencia del juez. Entonces, hay mil detalles específicos, ¿qué tal el tema de la prueba? Y entramos en una de las cuestiones candentes. De bastante tiempo a esta parte se viene discutiendo en torno a la inequidad, a la que puede conducir una aplicación rigurosa del tema o del régimen del onus probandi. Yo suelo contarles a mis alumnos de pregrado, o inventarles el ejemplo, del cartonero que le vende 50 kilos de cartón diario a la gran papelera, el cartonero es iletrado, sabe más o menos la capacidad que tiene el carrito para llevar, y lo entrega todos los días para que al final de la semana la papelera le entregue una liquidación. Si de pronto, un hijo del cartonero que aprendió a leer, sabe los números, le dice al padre mira, te están engañando porque te están pagando menos, y el cartonero quiere demandar, ¿a quién le corresponde probar la existencia de la obligación? Todos lo sabemos, ¿verdad? El artículo 1698 es implacable, y con esa primera palabra que hace que nos acordemos de su redacción, nos dirán que incumbe probar las obligaciones o su extinción, etc., etc. ¿les parece justo? ¿No les parece que esta gran empresa papelera, solamente apretando un botón o dos botones, puede decir exactamente cuánta fue la carga de papel que el cartonero Juan entregó el día miércoles 27 a las 3 y media de la tarde en la planta de tal parte? ¿¿No está todo computarizado? ¿No sería equitativo, entonces, que en esa discusión, que en esa enorme diferencia, la carga de la prueba la trasladáramos al otro lado? Eso da margen a lo que se Ilama la teoría de las cargas dinámicas o el principio de facilidad de la prueba. $Y$ cuando hablamos de los poderes del juez y entramos en la prueba, esto es un tema recurrente. $Y$ uno puede decidirse con entusiasmo claro ahí esta, que sea el juez el que determine quién pruebe, pero atención, darle esa atribución al juez, 
significa exponer a las partes a un riesgo fenomenal de indefensión, porque si el juez llega a esta conclusión al tiempo de la sentencia y resulta que yo soy el demandado y al juez le pareció que yo debí haber probado y esto me lo cobra en la sentencia, quiere decir que me va a condenar, sin que yo haya tenido real posibilidad de rendir esa prueba que a él le parecía estaba de mi cargo.

Entonces volvemos al tema, equilibrios, en este proyecto aceptamos esta teoría del desplazamiento del onus probandi, en función de que pruebe quien tiene más facilidad para hacerlo, pero a condición de que el juez, con la debida anticipación y tomando los resguardos del caso, se lo haya comunicado para que no se provoque indefensión, para que no se provoque sorpresa, ahí hay una aplicación concreta de este tema de los poderes del juez.

Quisiera rápidamente terminar con dos temas. Una cuestión recurrente es el tema de las ejecuciones, yo aventuré un número, dije que algunos estudios indican que hoy día hay más del 95\% de ingresos en el ámbito judicial con ejecuciones. Y cualesquiera que sean los números para abajo, 80, 85, 90, lo que sea, es claro que ese es el problema de la judicatura civil. ¿Cómo lo resolvemos? Ya hace mucho tiempo que todos llegamos a la conclusión que los problemas de la justicia no se resuelven, solamente, con más jueces. Esa es una simplona respuesta, inaceptable, cuando uno toca el tema con seriedad. O sea, no es un problema sólo de más jueces, hay que hacer algo más, y la reforma propone un paso francamente audaz, que es traer a nuestra realidad un modo que nos es enteramente desconocido, es traer el sistema germánico, que se Ilama el sistema germánico de ejecución, paradojalmente donde ha brillado y donde se ha desarrollado es en Francia, o sea, lo que pretendemos es desjudicializar la ejecución, confiándosela a funcionarios que no ejerzan funciones jurisdiccionales, esta es una reforma brutal diríamos, esto contraría lo que son nuestras tradiciones, nuestros hábitos, nuestras costumbres, nuestras prácticas. Pero hasta dónde queremos llegar, las estadísticas, ésas que yo echo tanto de menos, demuestran que en un número abrumador de ejecuciones no se oponen excepciones y entonces rige nuestra vieja regla que en tal evento bastará el mandamiento. Si eso es así, si no necesitamos la intervención judicial porque no hay excepciones, no resultará difícil que la ejecución le sea confiada a quien no ejerza función jurisdiccional y represéntense ustedes la idea de un síndico privado. Ese síndico, ese funcionario, que va a tener otro nombre, probablemente, oficial de ejecución, le vamos a entregar el título, para que él vaya donde el deudor y lo requiera de pago, otorgándole un plazo para que pague. Ahí, claro, aparece la primera gran dificultad, si el deudor no paga ¿puede este particular embargar? Bueno, en mi concepto, para que algo así llegue a ocurrir en nuestro país, a lo menos, se requeriría una reforma constitucional, porque me parece que el embargo afecta el dominio en su esencia y, en consecuencia, no hay modo como permitir que un particular tenga esa facultad. Pero supuesto 
que esa reforma existiera, permitimos que este síndico, que este funcionario requiera de pago, embargue, si no le paga, y luego se entre en una suerte de receso de 30 días. Durante ese lapso, el síndico que viene contratado por el acreedor, podrá buscar formas de entendimiento con el deudor, podrá además expresarle una opinión al acreedor. Puede ser que en ese lapso el deudor pague, concilie, arregle, pero puede ser que esté dispuesto a discutir jurisdiccionalmente el tema y en ese caso, el deudor requerido por el particular presentará su demanda ante el juez, que será una demanda contra el título, de modo que, figuradamente, por decirlo de alguna manera, será el deudor el que dé comienzo al juicio ejecutivo. ¿Cómo? Impugnando el título, oponiendo las excepciones, extremadamente reducidas, que la ley le va a autorizar, y entonces lo que era una sede enteramente extrajudicial, habrá devenido en un tema judicial, propuesto a iniciativa del deudor. Por ahí, entonces, encontramos una manera de desjudicializar esto, crear unos tribunales de ejecución que se encarguen de ese tema y descargamos a la judicatura ordinaria de lo que es esta tarea central.

El último punto que quiero tomar con ustedes, estoy ya pasado en el plazo, simplemente lo digo, es el tema de los recursos, ese es para mí un tema centralísimo. ¿Qué hacemos con los recursos? Cuando se plantea el tema de modificar un sistema procedimental, para generar un régimen de recursos, tiene dos cosas en mente: lo que quiero con el sistema de recursos es asegurar una respuesta jurisdiccional de calidad, para combatir el error, para corregir el error. Pero al propio tiempo, quiero que esa corrección se verifique en tiempos razonables, en tiempos prudentes. Se trata, pues, de armonizar calidad de la respuesta y celeridad de esa misma respuesta. Con esos parámetros hay que enfocar el tema de los recursos, ¿cómo lo hacemos? Bueno, hay muchas fórmulas, hay quienes han querido privilegiar una cosa sobre otra y entonces dicen, tratemos de eliminar los recursos, mientras menos recursos menos lentitud, más celeridad. De algún modo, para ser franco, la reforma del proceso penal discurrió en esa línea y copiando lo que había dicho un notable procesalista argentino de la década de los 40, Alfredo Vélez, lo que hizo fue poner un tribunal colegiado a la altura de lo que llamamos la primera instancia, que no es una primera instancia porque la resolución no es impugnable por apelación. ¿Por qué no? Simplemente, porque se dijo si la apelación se justifica porque 3 van a haber más que 1, entonces bajemos esos 3 a este nivel, y démosle a ellos que resuelvan el tema, con lo que no necesitamos tanto recurso, ¿verdad?. Ahí hay una clara toma de partido, pero nos topamos con algunos problemas no previstos, nos topamos, por ejemplo, con que la Corte Interamericana de Derechos Humanos, en julio de 2004, dictó una sentencia en el proceso Herrera-Ulloa con Costa Rica, y le dijo a los países de Latinoamérica que aquellos que no consagraran, que no tuvieran en su ordenamiento un recurso que permitiera la revisión de los hechos 
y el derecho, no satisfacían las exigencias de la Convención Americana de Derechos Humanos. En consecuencia, no es posible, dijo la Corte, eliminar el recurso que permite la revisión de los hechos y sustituirlo solamente por uno que permite la revisión del derecho. Esa regla, que para ser franco, es sorprendente que los penalistas no la estén usando todos los días, yo si me dedicara al proceso penal tendría todos mis asuntos en la Corte Interamericana, porque nuestro Código del proceso penal, sólo permite el recurso de nulidad, en el que no es lícito plantear cuestiones de hecho. Esa referencia de la Corte Interamericana sumado a lo que dijo la misma Corte en la opinión consultiva 11-90, en la que dijo que al proceso civil le eran aplicables enteramente las reglas y garantías del proceso penal, cierra un cuadro. Cuando uno habla de recursos en el proceso civil, no puede dejar de consagrar uno que permita que un tribunal superior haga lo que la Corte llama la revisión global de la sentencia, es decir, que revise las cuestiones de hecho y de derecho, ese es el tema, eso es lo que hay que poner. ¿Cómo lo hacemos? ¿Qué hace el proyecto? El proyecto nuevo lo que hace es que establece un recurso de apelación, al que le otorga la aptitud suficiente, no sólo para revisar las cuestiones de hecho y de derecho, como acontece hoy día, sino que, además, le confía el control de las cuestiones formales o de acatamiento de garantías procesales, en otras palabras, la nueva apelación perseguirá cumplir las finalidades de la apelación clásica y también aquellas que están confiadas a la casación en la forma. O sea, será un recurso de mérito y al mismo tiempo un recurso de nulidad, y con eso entonces formalmente están satisfechas las exigencias de la Corte, para ser franco, y este ya es un problema de estilo, de gusto, a mí me cuesta aceptar esta confusión, pero se corresponde con lo que se viene predicando, probablemente, desde Goldschmidt en adelante, con lo que se Ilama la teoría del recurso indiferente, y puede ser claro, se ajusta también de algún modo al Pacto, la Convención Americana, el artículo 25.1 de la Convención Americana de Derechos Humanos dice que los Estados deben asegurar la existencia de un recurso sencillo y eficaz, para la protección de los derechos. Y esto, un solo recurso de apelación, sin formalidades, cumple esas exigencias, un capítulo resuelto.

Nos queda para terminar la última tarea: ¿Qué hacemos con la Corte Suprema? ¿Vamos a mantener la casación? ¿Es necesaria la casación? Históricamente, la casación cumplió una función que se llama la función nomofiláctica, que era aquélla a través de la cual se protegía el ordenamiento jurídico. Más tarde se le agregó la función de unificación de jurisprudencia, y en Chile, a lo menos, se ha mantenido en esa línea. También el otro Goldschmidt, James, planteó una finalidad distinta, la función dikelógica de la casación, es decir, la casación orientada al logro de la justicia en la decisión. 
Para terminar con esta cosa absurda que de repente aparece en las sentencias de nuestra Corte de casación, es la que dice que ella es ajena al problema de justicia involucrado, que ese es un problema de los jueces del fondo y lo que a ella le corresponde es exclusivamente velar por la correcta aplicación del derecho, como si algún tribunal de justicia pudiera ser indiferente al tema de justicia involucrado.

Ese la situación, ese es el tema actual. En América Latina, qué se ha hecho con esto, se ha temperado el rigor de la casación. Por eso, en algunos países donde son dados a usar una terminología un poco exagerada, se habla de la casación bastarda, para decir que es una casación que se apartó de sus orígenes legítimos y puros, y entra entonces también en el ámbito de la revisión de los hechos. Así pasa, por ejemplo, en Uruguay, pasa de la misma manera en Argentina y en el Código colombiano. Pero nosotros no, para nosotros la casación es la francesa, aquella que venía del siglo XVIII, que se proyectó en el siglo XIX. ¿Qué hacemos con esa casación? ¿La mantenemos? Es que a aquellos de ustedes que no les han enseñado casación, permítanme decirles que todos los profesores vamos a decir que la casación es un instrumento para velar por la uniformidad del derecho, lo que constituye en la práctica un mito. Pocas cosas generan mayor grado de incertidumbre que la casación, y la generan básicamente por una razón, por una absurda dicotomía entre lo que se llama el error de hecho y el error de derecho, y en consecuencia, lo que en un recurso se califica de error de hecho y se excluye a la casación, en otro se califica de error de derecho, y nadie sabe con qué humor van a amanecer los jueces de casación para revolver estos problemas. En consecuencia, en materia de casación tenemos una incertidumbre atroz. ¿La mantenemos o la eliminamos? ¿Podemos darnos el lujo de eliminar a la Corte Suprema? ¿Será posible eliminarla? ¿Qué hizo este Código, este proyecto que se va a dar a conocer en los próximos meses? Generó una solución intermedia, enteramente, creo yo, insatisfactoria, miradas las cosas simplemente. Buscó un camino que hicimos con la reforma procesal penal, creó un recurso extraordinario, con el cual se puede ir a la Corte Suprema, en contra de decisiones inapelables de Cortes de Apelaciones, cuando esté involucrado un interés general y dice la ley que se entenderá involucrado un interés general cada vez que se hayan vulnerado de manera esencial las garantías y derechos otorgados por la Constitución o reconocidos por Tratados vigentes, celebrados por el país. Igualmente se entenderá comprometido el interés general, cuando la Corte estime necesario modificar, o cambiar, o actualizar un criterio jurisprudencial, en esos casos la Corte puede conocer del recurso extraordinario, éste que de modo excepcional se está consagrando, esa solución enteramente insatisfactoria, definitivamente, no hemos sabido resolver el problema. Es posible que cuando el Código se socialice verdaderamente en todo el país, aparezcan 
buenas soluciones. De momento, esas son las propuestas que, les repito, a mí por lo menos no me terminan de convencer.

Perdónenme, como me ha ocurrido tantas veces y no debiera sucederme, me extendí mucho más de lo que yo pensaba, por eso les doy una excusa y les agradezco que me hayan escuchado.

Muchas gracias. 